\title{
Work in Progress: How Do We Teach and Measure Systems Thinking?
}

\author{
Linda Vanasupaa, Erika Rogers, Katherine Chen
}

\begin{abstract}
Since the 1990's blue-ribbon commissions on engineering education have called for educators to graduate engineers who are capable of systems thinking. However, there is sparse information on how to cultivate this type of cognitive development. How do we develop and measure systems thinking? In this paper, we present the first of a series of methods that we are piloting to initiate the systems thinking process. This exercise, developed by Checkland and Scholes and called "Rich Pictures," requires the participant to express a reality in terms of images and connections between these images. We utilized the Rich Pictures exercise in combination with an appreciative inquiry strategy in pursuit of an initial research hypothesis regarding the impact of project-based learning on female students. We only partially answered our initial question, but the exercise unexpected yielded enthusiastic participation by the students and a rich set of data regarding unanticipated factors that influenced students' learning. The value of the activity is that it initiates the process of thinking nonlinearly, an important first step in students' cognitive development for systems thinking.
\end{abstract}

Index Terms - causal loop diagrams, rich pictures, soft systems methodology, systems thinking

\section{INTRODUCTION}

Despite the many calls for educational reform that place a high demand for engineering graduates to think holistically[1-3], there is little research-based information in the literature on how to develop this skill. This cognitive ability emphasizes seeing the whole, identifying trends over time and seeing connections that create these trends. As a cognitive activity, systems thinking challenges engineering students because it goes against the grain of typical engineering curricular approaches. For example, engineering curricula contain a strong analytical component, where the focus is to break a problem down into smaller components. In contrast, systems thinking requires seeing the whole. Oftentimes in engineering curricula, time is ignored as a variable (e.g., by assuming steady state conditions) to simplify the problem and enable a solution. The fact that systems have a dynamic nature, where properties change in time is a critical foundation of systems thinking. Engineers are often taught to think linearly and convergently. For example, $V=I x R$ is just one of the primary linear relationships that engineers utilize. Its remarkable simplicity enables engineering students to converge on an answer if a couple parameters are known. In contrast, mathematical models developed out of systems thinking are often non-linear models, stressing trends in time, rather than converging on a single answer. Clearly students need guidance within the curriculum if they are to develop this foreign way of viewing and addressing problems. Through the work discussed in this paper, we sought to initiate the process of developing and verifying methods that would enable students to more effectively think holistically.

\section{THE BASICS OF SYSTEMS ThINKING}

Much of the systems thinking literature has come from the business and organization world(e.g., see [4]), where the systems thinking tools have been effective at enabling organizational transformation[5]. As a way of approaching a problem, Anderson and Johnson[6] describe five characteristics of systems thinking which we quote here:

- Thinking of the "big picture";

- Balancing short-term and long-term perspectives;

- Recognizing the dynamic, complex and interdependent nature of systems;

- Taking into account both measurable and nonmeasurable factors.

Systems thinking practitioners utilize a few graphical tools to assist the process. One such tool is called "behavior over time" (BOT) graphs. These are usually schematic depictions of how an important variable behaves over time, although they can also include real data. Another tool that is used is a "causal loop diagram." These diagrams are similar to concept maps, showing how one concept (e.g., interest in a major) is linked to another (e.g., retention). The difference, however, is that causal loop diagrams depict how changes in one concept are linked to changes in another. For example, when "interest in a major" decreases, "retention" also decreases. Once a comprehensive causal loop diagram is created, one can begin addressing systemic problems.

\section{METHODS}

Pilot study participants were recruited from students who are majors in the Department of Materials Engineering. The Department Chair sent letters of invitation (including a copy of the Informed Consent Form) to 8 males and 8 females, thus ensuring representation of students at all four levels of academic standing (freshman, sophomore, junior and senior). The students were offered a movie ticket and a 
Certificate of Participation as incentives to participate in the project.

Seven women responded and were scheduled to meet on from 5 to $7 \mathrm{pm}$. Their ages ranged between 18 and 22 years of age, and the majority was of Caucasian ethnicity, with one Mexican American and one mixed Asian/Caucasian. Five of the seven participants had come to the Materials Engineering major at Cal Poly as their first choice, while the other two transferred in from other Cal Poly Engineering majors.

All eight of the male participants responded and met on the following day from 6 to $8 \mathrm{pm}$. They ranged in age from 19 to 26 years of age, and the majority was of Caucasian ethnicity, with two of Mexican American heritage, and one Asian/Caucasian. Seven of the eight came to the Materials Engineering major at Cal Poly as their first choice, while the oldest participant was a transfer student from another college.

The participants were given a brief explanation of the overall purpose and conduct of the activity. A brief PowerPoint overview of Soft Systems Methodology (SSM)[7] was then presented with the purpose of introducing the technique of SSM as a systems thinking approach. Checkland's specific concept of information gathering through "Rich Pictures" was emphasized, as a lead-in to the later activities. Examples of Rich Pictures were shown, and the presentation concluded with some references for further exploration.

After the presentation, the activity outline was reviewed with particular emphasis on the definition of "perceived efficacy," and the Materials Engineering Department's interest in improving this. This was followed by a warm up task, in which each participant individually listed his/her three top "desired effects" as outcomes of their engineering careers, and gave a personal rating of perceived efficacy i.e., how much does the individual believe that he/she can achieve his/her career outcomes.

\section{RESULTS AND DISCUSSION}

Each group generated a drawing depicting a "successful" engineering student and an "unsuccessful" engineering student. While space does not permit these images to be presented here, we have included the female group's depiction of the "unsuccessful" in Figure 1.

Images from male and female groups shared many themes, demonstrating the competing demands on their time. These included leisure activities, relationships, family, financial concerns, and time management. However, the major benefit of the rich pictures activity was that it enabled each group of students to generate more than ten individual factors influencing their success, enabling the next step of constructing an accurate causal loop diagram.

Incidentally, the researcher observed that all students were enthusiastically engaged in the activity of constructing the Rich Pictures and indicated their desire to use the method within the curriculum to enable "out of the box" thinking. We suspect that part of its appeal to engineering students, aside from the fact that there were no negative consequences to doing it, was that it engaged right-brain functions of social exchange and creativity.

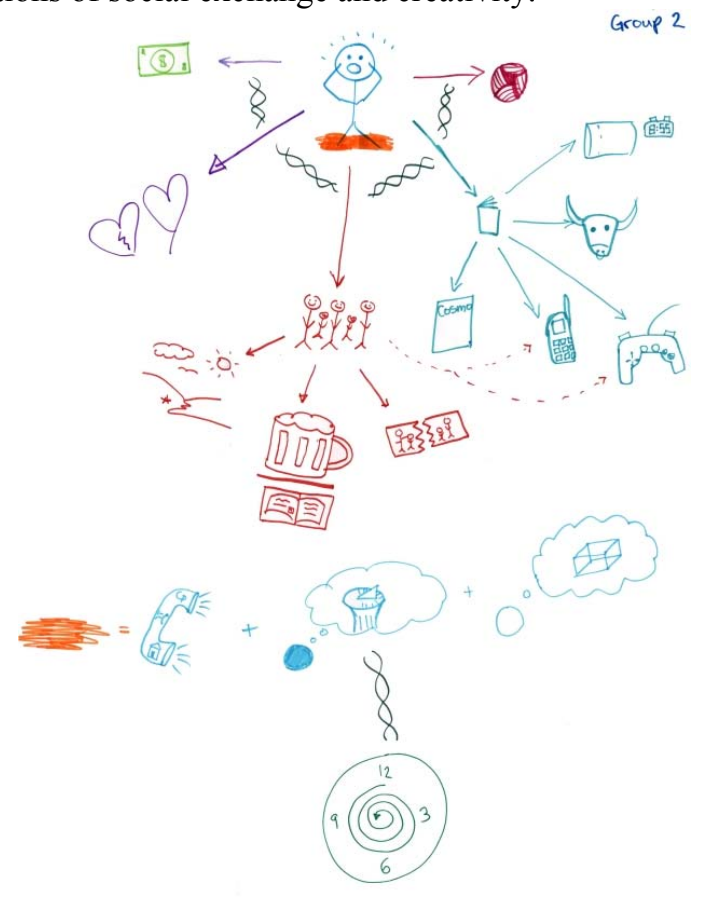

FIGURE 1. FEMALE GROUP'S “UNSUCCESSFUL" STUDENT

\section{SUMMARY}

SSM and Rich Pictures appears to serve as a viable activity to broaden students' consideration of systemic factors, a precursor to systems thinking.

\section{ACKNOWLEDGMENT}

This work is supported in part by a grant from the National Science Foundation (Grant\#EEC-0530760). The viewpoints expressed are those of the authors and do not necessarily reflect those of the National Science Foundation.

\section{REFERENCES}

[1] Jamieson, L., "Keynote of the American Society for Engineering Education Annual Conference 2007," 2007.

[2] The Engineer of 2020: Visions of Engineering in the New Century. Washington DC: National Academy Press (U.S.), 2004.

[3] Duderstadt, J. "Engineering for a Changing World: A Roadmap to the Future of Engineering Practice, Research, and Education," The University of Michigan, Ann Arbor, MI 2008.

[4] P. Senge, C. O. Scharmer, J. Jaworski, and B. S. Flowers, Presence: Exploring Profound Change in People, Organizations, and Society. New York: Currency Doubleday, 2004.

[5] B. Sugarman, "A Learning-Based Approach to Leading Change," The PricewaterhouseCoopers Endowment for The Business of Government 2006.

[6] V. Anderson and L. Johnson, Systems Thinking Basics: From concepts to Causal Loops vol. 7. Waltham, Massachusetts, 1997.

[7] P. Checkland and J. Poulter, Learning for Action. New York, NY: John Wiley \& Sons, 2006. 